\title{
In-air vocal repertoires of spotted seals, Phoca largha
}

Peijun Zhang, Jiaojiao Lu, Songhai Li, Jiabo Han, Qinguo Wang, and Liangliang Yang

Citation: The Journal of the Acoustical Society of America 140, 1101 (2016); doi: 10.1121/1.4961048

View online: https://doi.org/10.1121/1.4961048

View Table of Contents: http://asa.scitation.org/toc/jas/140/2

Published by the Acoustical Society of America

\section{Articles you may be interested in}

Classification of underwater vocalizations of wild spotted seals (Phoca largha) in Liaodong Bay, China

The Journal of the Acoustical Society of America 141, 2256 (2017); 10.1121/1.4979056

Quantitative classification of harbor seal breeding calls in Georgia Strait, Canada

The Journal of the Acoustical Society of America 140, 1300 (2016); 10.1121/1.4961008

Conditioned hearing sensitivity change in the harbor porpoise (Phocoena phocoena)

The Journal of the Acoustical Society of America 140, 960 (2016); 10.1121/1.4960783

Nearfield and farfield measurements of dolphin echolocation beam patterns: No evidence of focusing

The Journal of the Acoustical Society of America 140, 1346 (2016); 10.1121/1.4961015

Temporal and spatial variation in harbor seal (Phoca vitulina L.) roar calls from southern Scandinavia

The Journal of the Acoustical Society of America 141, 1824 (2017); 10.1121/1.4977999

Effects of a near-field rigid sphere scatterer on the performance of linear microphone array beamformers The Journal of the Acoustical Society of America 140, 924 (2016); 10.1121/1.4960546 


\title{
In-air vocal repertoires of spotted seals, Phoca largha
}

\author{
Peijun Zhanga) \\ Sanya Key Laboratory of Marine Mammal and Marine Bioacoustics, Institute of Deep-sea Science \\ and Engineering, Chinese Academy of Sciences, Sanya 572000, China \\ Jiaojiao Lu \\ Computer Teaching Center, Sanya University, Sanya 572000, China \\ Songhai $\mathrm{Li}^{\mathrm{b})}$ \\ Sanya Key Laboratory of Marine Mammal and Marine Bioacoustics, Institute of Deep-sea Science \\ and Engineering, Chinese Academy of Sciences, Sanya 572000, China \\ Jiabo Han \\ Liaoning Key Laboratory of Marine Biological Resources and Ecology, Liaoning Ocean and Fisheries \\ Science Research Institute, Dalian 116023, China \\ Qinguo Wang \\ Dalian Sun Asia Tourism Holding Company, Limited, Dalian 116023, China
}

Liangliang Yang

MOE Key Lab of Underwater Acoustic Communication and Marine Information Technology, Department of Applied Ocean Physics and Engineering, Xiamen University, Xiamen 361000, China

(Received 17 January 2016; revised 14 July 2016; accepted 29 July 2016; published online 17 August 2016)

Spotted seals (Phoca largha) are thought to be less vocal than other phocids. However, acoustic communication behaviors of spotted seals have been reported several times. In this study, the vocal repertoires of spotted seals housed in Dalian Sun Aquarium, China were recorded and analyzed. The frequencies of the sounds made by the seals ranged from 139.3 to $2323.1 \mathrm{~Hz}$, and the time durations lasted from 92.8 to $1208 \mathrm{~ms}$, depending on age and gender $(P<0.01)$. The peak-to-peak sound source levels were $109-124 \mathrm{~dB}$ re $20 \mu \mathrm{Pa}$. In total, seven vocal types were identified: pup call, yearling call, bark, growl, grunt, moo, and throat guttural. The pups emitted sounds with high frequencies $\left(\mathrm{F}_{1}: 972.4 \pm 374.4 \mathrm{~Hz}\right.$, mean \pm standard deviation) and medial time durations (564 $\pm 178 \mathrm{~ms}$ ); when the pups grew older, the sounds became yearling calls, which had high frequencies with median (interquartile range) of $1198.0(821.7-1385.5) \mathrm{Hz}$; and long time durations [902 (745-1080) ms]. The male adults emitted sounds with low frequencies [430.2 (388.2-486.7) $\mathrm{Hz}$ ] and short time durations [334 (233-599) $\mathrm{ms}$ ], while the female adults emitted sounds with medial frequencies [814.5 (592.6-1024.3) Hz] and medial time durations [531 (336-688) ms].

(c) 2016 Acoustical Society of America. [http://dx.doi.org/10.1121/1.4961048]

[WWA]

Pages: $1101-1107$

\section{INTRODUCTION}

Acoustic communication plays an important role in various aspects of pinniped behavior. For the majority of species, mother-pup reunions, establishment of territories, and male-male competition during the mating season are examples of behaviors known to be mediated by vocal signaling. Acoustic measurements therefore provide an essential tool to study ice-breeding pinnipeds; remote sound recordings can be used to track and determine seasonal changes in animal movement and behavior (Van Parijs and Kovacs, 2002; Van Opzeeland et al., 2008).

Vocalization descriptions (e.g., call purpose, call type, and sound parameter) are important types of acoustic

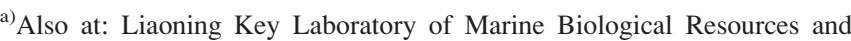
Ecology, Liaoning Ocean and Fisheries Science Research Institute, Dalian 116023, China.

${ }^{b)}$ Electronic mail: lish@idsse.ac.cn
}

measurements for pinnipeds. They are commonly used as the basic data to help understand the acoustic behavior of the animals. Vocalization descriptions have been reported for many pinniped species, such as bearded seals (Erignathus barbatus), ringed seals (Phoca hispida), harbor seals (Phoca vitulina), hooded seals (Cystophora cristata), harp seals (Pagophilus groenlandicus), Mediterranean monk seals (Monachus monachus), Australian fur seals (Arctocephalus pusillus), and South American fur seals (Arctocephalus australis) (Ballard and Kovacs, 1995; Phillips and Stirling 2001; Muñoz et al., 2011; Rautio et al., 2009; Risch et al., 2007; Serrano, 2001; Tripovich et al., 2008; Van Parijs and Kovacs, 2002). In addition to vocalization descriptions, further sound parameter analyzes have been conducted on species that emit harmonic (tonal) calls, to evaluate mother-pup recognitions and reunions, with the aim of explaining pinniped breeding strategies (Van Opzeeland et al., 2008).

Scientists generally agree that vocal recognition is widespread in pinnipeds. It is considered better developed in 
otariids than in phocids, due to their different nursing strategies (Insley et al., 2003; Van Opzeeland et al., 2008). This is because of studies that have clearly shown vocal signaling plays an important role in successful otariid mother-pup reunions, upon the return of mothers from their regular foraging trips. In phocids, the role of vocal signals in the mother-pup recognition process appears more variable and has, to date, only been investigated in a few species [see review in Van Opzeeland et al. (2008)].

Spotted seals (Phoca largha) are ice-breeding phocids, found in eight breeding colonies worldwide (Rugh et al., 1997). They exhibit a seasonal breeding pattern, with annual and synchronous cycles (Atkinson, 1997). They were once considered one of the less vocal phocid species (Bigg, 1981; Van Parijs and Kovacs, 2002). According to the authors' careful observations, the spotted seal is generally silent, but becomes much more clamorous during the breeding season. Vocal signals were proved to play an important role in reproduction communication for this species (Beier and Wartzok, 1979; Gailey-Phipps, 1984); however, very few studies have been conducted to understand their vocal repertoires and characteristics by now.

Liaodong Bay $\left(38^{\circ} 43^{\prime}-40^{\circ} 58^{\prime} \mathrm{N}, 119^{\circ} 50^{\prime}-122^{\circ} 18^{\prime} \mathrm{E}\right)$, in China, has the southernmost breeding colony of the spotted seal. Dalian Sun Asia Aquarium (DSAA; $38^{\circ} 52^{\prime} \mathrm{N}, 121^{\circ} 34^{\prime} \mathrm{E}$ ), located beside Liaodong Bay, is an important rescue center for wild spotted seals in China. There is a fairly large population of previously wild adult spotted seals in DSAA, which has rescued about 50 individuals since it opened in 1994. All of the adult seals at DSAA were rescued from the Liaodong Bay colony. In addition, close to 10 calves are born and grow naturally in the aquarium each year.

In the present study, we collected vocal data from the spotted seals at DSAA to describe their in-air vocal repertoires and acoustic characteristics. The study provides basic data to help scientists understand the in-air vocal repertoires of this species and help fill current understanding gaps of vocalization behavior in phocid seals. The results can be used to evaluate the mother-pup reunion abilities of spotted seals and provides a basis for implementing acoustic monitoring, to aid the conservation of spotted seal populations.

\section{MATERIALS AND METHODS}

\section{A. Ethical statement}

This study was conducted under a permit issued by Liaoning Fisheries Administration Bureau, Liaoning Province, China (approval number: LSYXFZ20111105).

\section{B. Sampling}

The vocal behaviors of spotted seals in captivity at DSAA were continually monitored for a whole breeding cycle (February 1, 2013-January 31, 2014). They were collected at specific times, depending on age of the seals. Sounds made by pups, yearlings, adult females and adult males were collected separately. The sounds made by pups and adult females were collected for $3 \mathrm{~h}$ every day, from an indoor breeding enclosure that contained 10 mother-pup pairs, during the lactation period
(February 28-March 6, 2013). The sounds made by yearlings were collected from individuals (four male, four female; aged 10-12 months), for $2 \mathrm{~h}$ every 15 days (December 1 , 2013-February 28, 2014), during feeding time and enclosure cleaning time, when the yearling calls were easier to record. The sounds made by adult males were collected from an outdoor enclosure, containing 10 males and 17 females for $2 \mathrm{~h}$ every 10 days, during mating time, in March 2013. Adult sounds were recorded at 18:00-21:00 in the evening when environment background noise declined. Seals were previously observed willing to call at this time period.

Vocal signals were recorded using a $46 \mathrm{AE} 1 / 2^{\prime \prime}$ Freefield Microphone Set (GRAS, Holte; sensitivity of $-120 \mathrm{~dB}$ re: $1 \mathrm{~V} / 20 \mu \mathrm{Pa}$; frequency range of $3.5 \mathrm{~Hz}-20 \mathrm{kHz}$ with sensitivity of $\pm 2 \mathrm{~dB}$ and $5 \mathrm{~Hz}-10 \mathrm{kHz}$ with sensitivity of $\pm 1 \mathrm{~dB}$ ) combined with a National Instruments USB-4431 data acquisition card (NI, Austin, TX) and a notebook computer. The distance between the microphone and phonating seals was 3-8 $\mathrm{m}$. A distance scale was marked before each recording and the real-time distance between the microphone and phonating seals was noted during the sound signal recordings. Sampling rate during recording was set to $16 \mathrm{kHz}$.

\section{Data analysis}

All recordings were analyzed as spectrograms in Matlab R2010b (Mathworks, Natick, MA). Time and frequency features of the in-air vocals made by the spotted seals were interpreted directly from the sound spectrograms (sampling rate: $16 \mathrm{kHz}$; scale: $\mathrm{dB}$ re: $1 \mathrm{~V}^{2}$; hamming windows: 1024 points and 50\%; analyzing bandwidth: $5.8 \mathrm{~Hz}$ ), by evaluating their color depth; color depth is correlated with the sound intensity levels. Only the signals with distinct and measureable vocal contours, which typically had $\mathrm{S} / \mathrm{N}$ ratios over $20 \mathrm{~dB}$, were used for further analysis.

Designations and descriptions of vocal types for the seals were mostly defined according to previous studies (Beier and Wartzok, 1979; Gailey-Phipps, 1984; Van Parijs and Kovacs, 2002; Risch et al., 2007; Rautio et al., 2009). Vocal types were also designated according to age class, harmonic, and call behaviors. The vocal characteristics that were measured in this study are described in Table I and Fig. 1; the vocal repertoires and characteristics of pups, yearlings, adult females, and adult males were identified and analyzed separately. Sound parameter comparisons between two groups of different age or gender class were analyzed by MannWhitney $U$ test using SPSS 13.0 (SPSS Inc., Chicago, IL). Data obeying normal distribution were described as mean \pm standard deviation (SD). Sound parameter from a single call type generally obeyed normal distribution, and was described in this way. Otherwise, data obeying skewed distribution were described as median (interquartile range). Sound parameters from one age or gender class, which were composed of data from several call types, usually obey skewed distribution, and were therefore described in this way. Source level is the amplitude (usually peak-to-peak) of sound measured at $1 \mathrm{~m}$ from the animal (Richardson et al., 2013); the source levels in this study were calculated according to the method described by Rogers (2014). 
TABLE I. Descriptions of the variables measured to characterize the spotted seal vocalization behaviors.

\begin{tabular}{|c|c|}
\hline Vocal characteristics & Description [mostly refer to Tripovich et al. (2008)] \\
\hline $\begin{array}{l}\text { Vocal duration } \\
\text { (dur) }\end{array}$ & Total duration of the call (ms). \\
\hline $\begin{array}{l}\text { Peak frequency } \\
\left(\text { peak } F_{1}\right)\end{array}$ & It describes the location of the band that has the most energy distributed in it $(\mathrm{Hz})$. \\
\hline $\begin{array}{l}\text { Second peak frequency } \\
\left(\text { peak } \mathrm{F}_{2}\right)\end{array}$ & It describes the location of the band that has the second most energy distributed in it $(\mathrm{Hz})$. \\
\hline $\begin{array}{l}\text { Third peak frequency } \\
\left(\text { peak } \mathrm{F}_{3}\right)\end{array}$ & It describes the location of the band that has the third most energy distributed in it $(\mathrm{Hz})$. \\
\hline Fundamental frequency $\left(\mathrm{F}_{0}\right)$ & Lowest visible ${ }^{a}$ harmonic of the vocal $(\mathrm{Hz})$, especially for pups. \\
\hline $\begin{array}{l}\text { Highest frequency } \\
(\mathrm{hF})\end{array}$ & Highest visible harmonic of the vocal $(\mathrm{Hz})$, especially for pups. \\
\hline $\begin{array}{l}\text { Frequency width } \\
(\mathrm{Fw})\end{array}$ & hF minus $\mathrm{F}_{0}(\mathrm{~Hz})$, especially for pups and youths. \\
\hline $\begin{array}{l}\text { Harmonic number } \\
(\mathrm{HN})\end{array}$ & Visible harmonic number, especially for pups. \\
\hline p-p SL & Peak-to-peak source level. \\
\hline
\end{tabular}

${ }^{\mathrm{a}}$ Note: Visible indicates harmonic with power larger than that of $10 \%$ peak $\mathrm{F}_{1}$.

\section{RESULTS}

\section{A. Call types}

In total, 679 sounds with a high signal to noise ratio were separated and analyzed. Seven vocal types were identified according to previous description (Beier and Wartzok, 1979; Gailey-Phipps, 1984; Tripovich et al., 2008): pup call, yearling call, moo, bark, growl, grunt, and throat guttural.

\section{Pup call}

Pup call (peak $\mathrm{F}_{1}=972.4 \pm 374.4 \mathrm{~Hz} ; \quad$ dur $=564$ $\pm 178 \mathrm{~ms} ; \mathrm{HN}=6.9 \pm 3.4$; mean $\pm \mathrm{SD}$ ) was a typical tonal

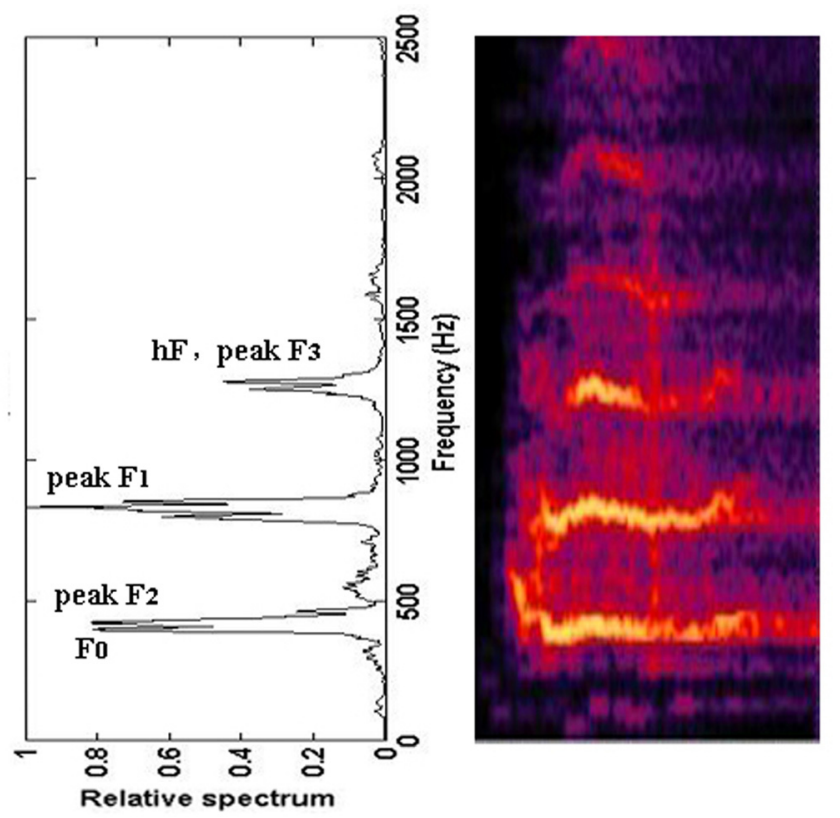

FIG. 1. (Color online) A spectrogram of a spotted seal pup call $\left(\mathrm{F}_{0}\right.$ $=$ fundamental frequency, peak $F_{1}=$ peak frequency, peak $F_{2}=$ second peak frequency, peak $\mathrm{F}_{3}=$ third peak frequency, and $\mathrm{hF}=$ highest frequency). sound and only produced by nursing pups [Fig. 2(A)]. It included harmonic, sub-harmonic, or both components.

\section{Yearling call}

Yearling call (peak $\mathrm{F}_{1}=1112.6 \pm 311.9 \mathrm{~Hz}$; dur $=971$ $\pm 320 \mathrm{~ms}$ ) was the sound emitted by yearlings and most like an adult growl [Fig. 2(B)]. Tonal and pulse signals were detected in the yearling call.

\section{Moo}

Moo was a low frequency nasal sound, similar to a cow's call [Fig. 2(C)]. The vocalization was recorded in both adult females (peak $\mathrm{F}_{1}=355.8 \pm 126.6 \mathrm{~Hz}$; dur $=815$ $\pm 99 \mathrm{~ms}$ ) and males (peak $\mathrm{F}_{1}=206.9 \pm 86.6 \mathrm{~Hz}$; dur $=651$ $\pm 232 \mathrm{~ms}$ ). This sound was rarely recorded.

\section{Bark}

Bark was a very common vocalization type in the spotted seals widely used in different behavioral situations [Fig. 2(D)]. It was a short pulse signal emitted by both adult females (peak $\mathrm{F}_{1}=798.0 \pm 272.7 \mathrm{~Hz}$; dur $=588 \pm 213 \mathrm{~ms}$ ) and adult males (peak $\mathrm{F}_{1}=451.9 \pm 68.7 \mathrm{~Hz}$; dur $=236 \pm 68 \mathrm{~ms}$ ). Yearlings could also bark, but seldom did.

\section{Growl}

Growl was also common in the spotted seals. Growl had the same spectrogram structure as that of bark, but its duration lasted much longer [Fig. 2(E)]. Growl was emitted by both adult females (peak $F_{1}=1083.1 \pm 111.9 \mathrm{~Hz} ; \quad$ dur $=1208$ $\pm 539 \mathrm{~ms}$ ) and adult males (peak $\mathrm{F}_{1}=444.3 \pm 58.2 \mathrm{~Hz}$; dur $=626 \pm 120 \mathrm{~ms}$ ). While the yearling calls sounded like adult growl, they commonly had a higher frequency and longer duration than the adult growl. 


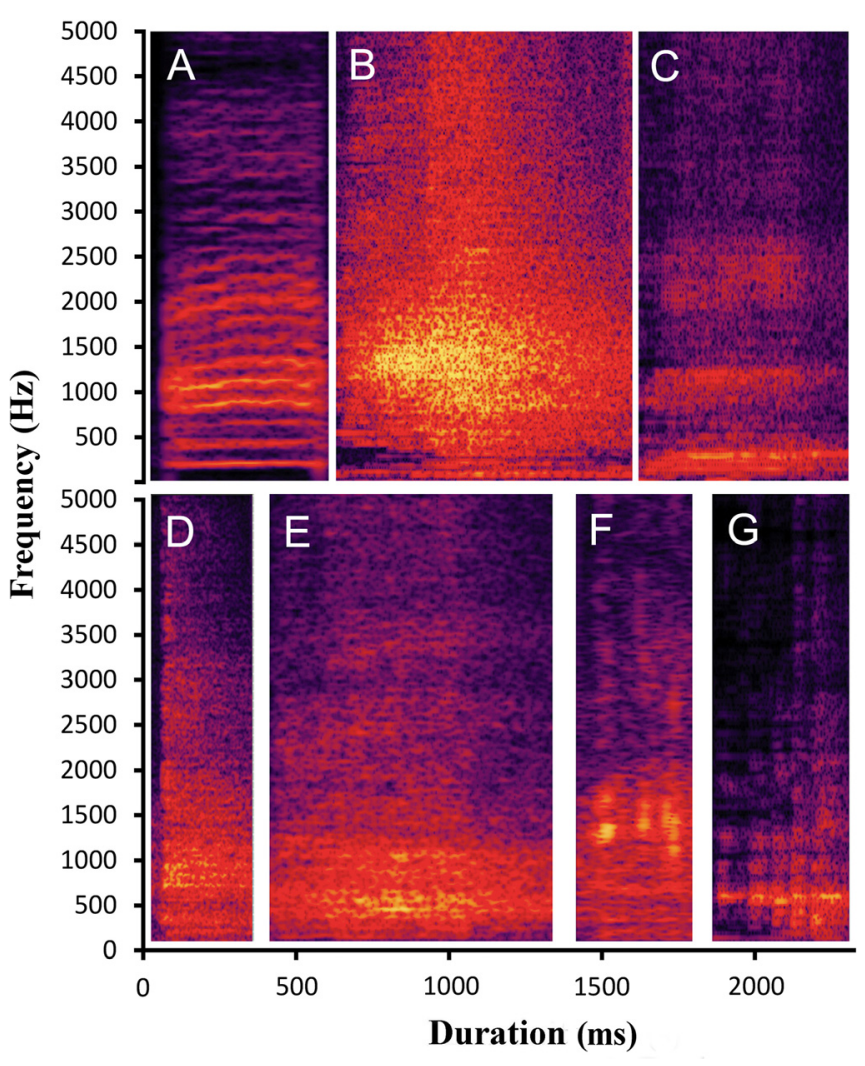

FIG. 2. (Color online) Selected spectrograms of different kinds of spotted seal vocals. (A) Pup call, (B) yearling call, (C) moo, (D) bark, (E) growl, (F) grunt, and (G) throat guttural.

\section{Grunt}

Grunt (peak $\mathrm{F}_{1}=877.2 \pm 331.8 \mathrm{~Hz}$; dur $=350 \pm 177 \mathrm{~ms}$ ) was short nasal sounds, with one or two syllables and was only recorded in adult females [Fig. 2(F)]. It was the most common sound used by the adult females during the nursing period.

\section{Throat guttural}

Throat guttural (commonly three to five syllables; peak $\mathrm{F}_{1}=504.2 \pm 46.1 \mathrm{~Hz}$; dur $=417 \pm 302 \mathrm{~ms}$ ) was a series of vocal sounds [Fig. 2(G)]. The spectrogram of a throat guttural looked like that for an underwater series of knocking sounds (Rautio et al., 2009). The difference was that the throat gutturals only had one peak narrow frequency band, while the band of the series of underwater knocking sounds was broad. Throat gutturals were rarely made and were only recorded from adult males over the study period.

\section{B. Call purposes}

During non-breeding seasons, the spotted seals were nearly silent and sounds were seldom recorded. However, during breeding season they became much more clamorous. For example, in a 5-min audio (recorded at 16:30 p.m. during courtship), the spotted seals were making sounds for about 2 min. Spotted seals were commonly observed emitting sounds during the following behavioral contexts: pups seeking help, yearling keeping reticent, adult males competing for mates (female attraction, male-male competition, and territory defense), and adult females nursing (pup protection and attraction).

Pups $<2$ months were quite noisy. They emitted sounds frequently when they felt helpless or scared. Pups were only able to produce one sound type, which was used for attracting cows and expressing emotion. As the pups grew older becoming yearlings, they gradually turned quieter, except when they were severely disturbed or threatened. Barks were sometimes recorded when the yearlings were scared. However, the yearlings did not emit barks to express their anger, or more exactly, fear; they preferred to make yearling calls to express their fear, dissatisfaction, and other negative emotions. The yearlings generally emitted one vocal type, which was the yearling call. The yearling call may be a stage of development between the tonal pup sound and pulse adult sound. Adult females were generally quiet, even during mating season. The only period when females preferred to emit sounds was during nursing. In nursing period, females emitted barks to protect their calf and defend their territory, emitted growls to attract their calf and express emotions, and emitted single grunts or a series of grunt signals to express slight dissatisfaction or grumble. Adult males were observed as quite noisy only during the mating season. In that period, males emitted barks to attract females, defend territory, and compete against companions; and emitted growls to attract females and express willingness to mate or other emotions. Besides, moo might be used to express an emotion for both adult females and males, but were unsure of the type of emotion.

\section{Vocal characteristics (description and comparison)}

Spotted seals pups emitted harmonic (tonal) sounds before molting, and began to emit chaos (pulse) sounds after weaning, when they learned how to bark. By the time the seals became yearlings, tonal sounds were mostly replaced by pulse sounds. The adults seemed to only emit pulse vocals.

Generally, the spotted seals emitted sounds with low frequency and short time durations. The sound frequency ranged from $139.3\left(\mathrm{~F}_{0}\right)$ to $2323.1(\mathrm{hF}) \mathrm{Hz}$, with peak $\mathrm{F}_{1}$ at 206.9-1112.6 Hz. Time duration lasted from 92.8 to $1208.0 \mathrm{~ms}$. Peak-to-peak source levels ranged from 103.2 to $124.4 \mathrm{~dB}$ re $20 \mu \mathrm{Pa}$, depending on vocal types. Descriptive statistics of the sound parameters for different vocal types are listed in Table II.

The peak $F_{1}$ and time duration of the pup calls, yearling calls, adult male calls and adult female calls were analyzed to compare vocalization differences among gender and age class (Fig. 3). Figure 3 shows that the pups emitted sounds with high frequencies and medial time durations; the yearlings emitted sounds with high frequencies and long time durations; the adult females emitted sounds with medial frequencies and medial time durations; and the adult males emitted sounds with low frequencies and short time durations. Statistical analysis of the data revealed that the peak $\mathrm{F}_{1}$ values of the adults [455.1 (395.4-595.0) Hz, interquartile range], both for the females [814.5 (592.6-1024.3) Hz] and males [430.2 (388.2-486.7) Hz], were significantly lower than those of the pups $(972.4 \pm 374.4 \mathrm{~Hz})$ and yearlings [1198.0 (821.7-1385.5) Hz] (Mann-Whitney $U$ test, 


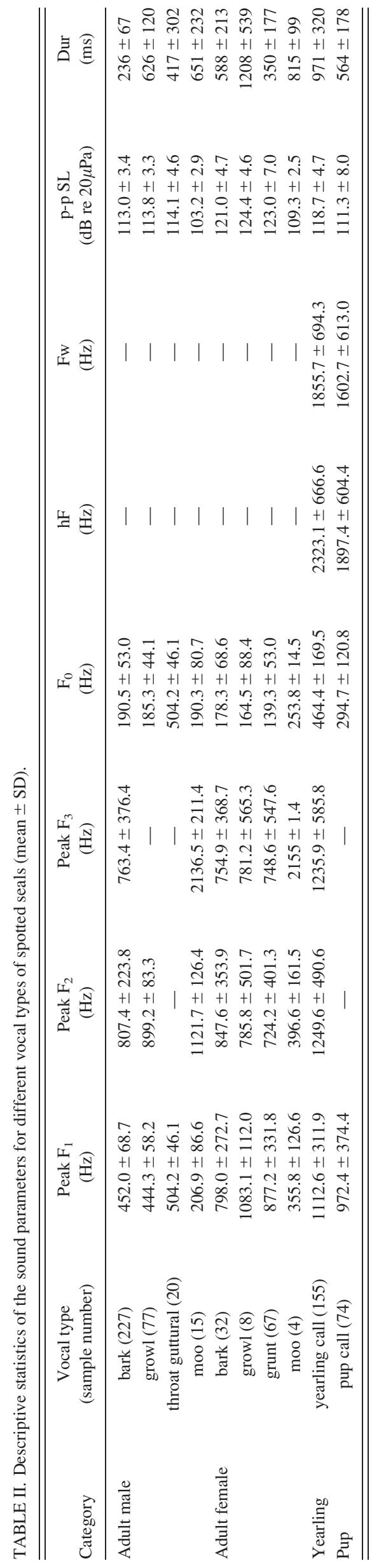

$p<0.01)$. The peak $F_{1}$ values of the calls made by the pups and yearlings were not significantly different (MannWhitney $U$ test, $p>0.05$ ). The peak $\mathrm{F}_{1}$ values of the male calls were significantly lower than those of the female calls (Mann-Whitney $U$ test, $P<0.01$ ). There were also significant differences in time duration among the pup calls (564 $\pm 178 \mathrm{~ms})$, yearling calls [902 (745-1080) ms], and adult male calls [334 (233-599) ms]; and among the yearling calls, adult male calls and adult female calls [531 (336-688) ms] (Mann-Whitney $U$ test, $p<0.01$ ). No significant differences in time duration were found between the pup calls and adult female calls (Mann-Whitney $U$ test, $p>0.05$ ).

\section{DISCUSSION}

The vocal signals reported in the present study were collected from captive spotted seals; they may not reflect the true status of the wild population. However, as there has not been a study of the in-air vocal repertoire of wild spotted seals, the current results are valuable towards increasing our understanding of the acoustic behavior of spotted seals. Overall, the results indicate that spotted seals may be more vocal than expected and their vocal behaviors seem to be mainly performed for reproduction purposes.

Acoustic communication of spotted seals has been previously described based on long time monitoring of a captive seal couple (Beier and Wartzok, 1979; Gailey-Phipps, 1984). The previous description indicated that their vocalization did not show significant changes in structural parameters over years or between the genders and no vocal signal was recorded until the animals attained sex maturity. Obviously, according to the present study there are some fairly differences documented on seal vocals: first, spotted seals were capable to vocal just after birth and were quite noisy before weaning, then gradually turned quiet until they attained sex maturity; second, significant difference in sound parameters between different age and sex classes was observed. Drum was previously documented by Gailey-Phipps (1984). However, the drum was seldom recorded in captive population in air in the present study, although it was recorded as an underwater signal at mating season in the wild at Liaodong Bay colony during a field recording.

The spotted seal and the harbor seal ( $P$. vitulina) are sibling species. In the vocal repertoires of these two species, the peak $F_{1}$ values of the harbor seal are higher than those of spotted seals (Van Parijs and Kovacs, 2002). This implies that the sounds made by the harbor seals have better directionality than those of the spotted seals. Four vocal types (pup call, bark, growl and grunt) have been documented in both species, with obvious absence of a tonal vocal (honk) in the spotted seals inferred from the present study (Van Parijs and Kovacs, 2002). According to current knowledge, the tonal voice is an essential sound for pup-mother recognition (e.g., Khan et al., 2006; Insley, 1992; Insley et al., 2003), which indicates, from the present results, that spotted seals would be relatively poor at vocal recognition.

Previously studies theorized that reproduction strategy might have been an important factor driving the evolution of acoustic strategy in pinnipeds (Insley, 1992; Insley et al., 

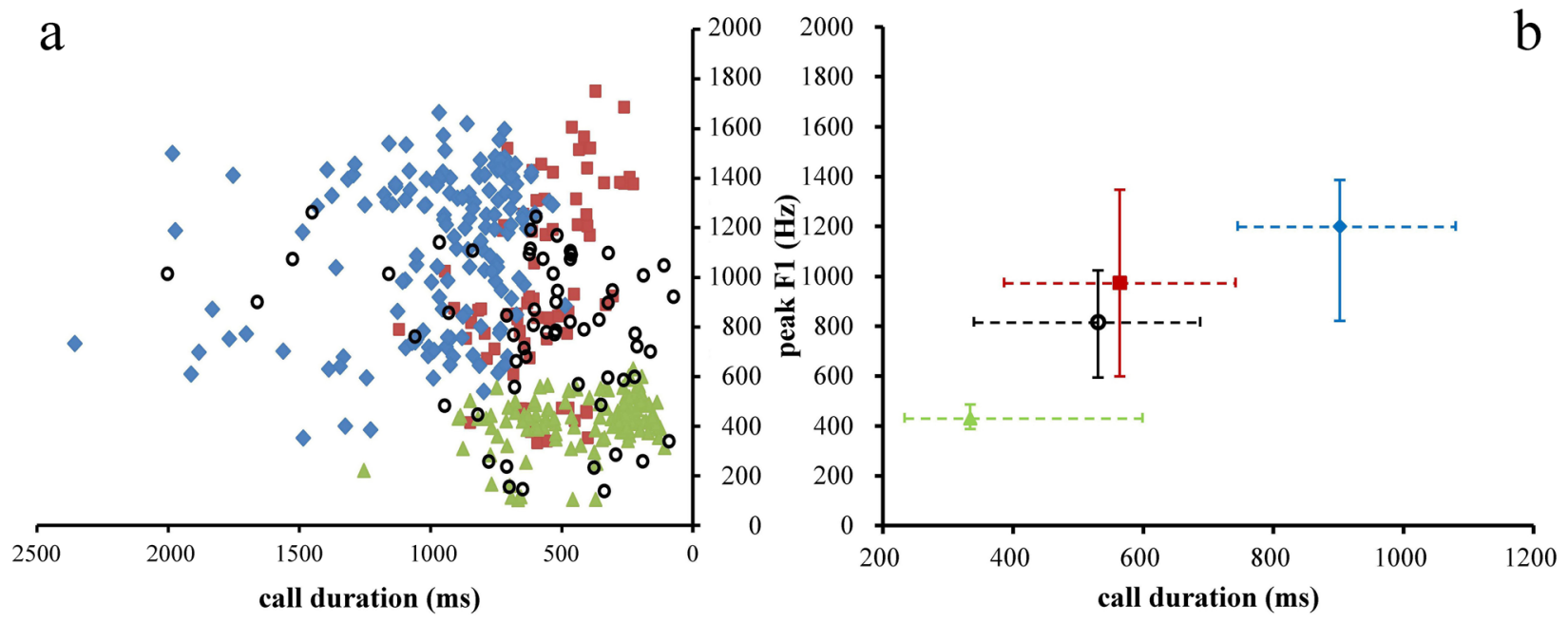

FIG. 3. (Color online) Scatter plots (a) and mean values (b) of peak $F_{1}$ values versus time duration, for the pup calls (squares), yearling calls (diamonds), adult female calls (circles), and adult male calls (triangles).

2003). The spotted seal and the harbor seal have evolved quite different reproduction strategies. Spotted seals breed on pack-ice and adopt a typical phocid maternal strategy, in which the mothers fast during the lactation period (Atkinson, 1997; Jefferson et al., 2007); in contrast, harbor seals breed on land and adopt an "otariid-like" maternal strategy, in which the mothers forage at sea after the first week of the lactation period (Boness et al., 1994). According to this theory, harbor seals should have evolved to be more efficient at vocal recognition, comparing to spotted seals. The acoustics of harbor seals have been well documented in several studies, such as their call characters (Van Parijs and Kovacs, 2002), pup vocal development (Khan et al., 2006), parentoffspring recognition (Sauve et al., 2015), and their hearing sensitivity and thresholds (Kastelein et al., 2009; Kastelein et al., 2013). However, for spotted seals, their acoustics information is much poor. According to the results presented in this study, spotted seals emit pulsing sounds of low frequencies, indicating weaker mother-pup vocal recognition abilities and lower sound directionality comparing to harbor seals, supporting the theory mentioned above.

As previously noted, Liaodong Bay is the southernmost habitat of spotted seals in the world; meanwhile, it is an important ocean shipping access point for the Chinese Northeast Asian Economy Zone. In recent years, seals in Liaodong Bay have been severely disturbed by human activities, including ocean traffic, harbor and coastal expressway constructions, oil exploitation, and aquaculture, among others (e.g., Boveng et al., 2009). Noise pollution has become an important environmental factor that may affect the survival of the seals in their habitat. The present study has documented the basic sound parameters (frequencies of different age classes and peak-to-peak sound pressure levels) of this species, which will be helpful for creating conservation measures in terms of reducing potential noise impacts on the animals. Our study has also shown significant differences in the sounds between the pups and adults, and male and female spotted seals. These characteristics may provide a basis towards using acoustic monitoring to determine the age composition and gender ratio of spotted seal populations in the wild.

\section{ACKNOWLEDGMENTS}

We gratefully acknowledge Xiao Xu from Institute of Deep-sea Science and Engineering, Chinese Academy of Sciences for his assistance of audio format transform and signal analysis. We thank the staffs from DSAA for their assistance in monitoring the vocal behavior of spotted seals and collecting sound signal. This work was supported by the Ocean Park Conservation Foundation Hong Kong (MM09_1213), the Doctoral Initial Fund of Liaoning Province (20141170), the National Natural Science Foundation of China (Nos. 41306169 and 41422604), the "Hundred Talents Program" of the Chinese Academy of Sciences (SIDSSE-BR315 201201, Y410012), the Knowledge Innovation Program of the Chinese Academy of Sciences (SIDSSE-316 201210), the Advanced Project in Young Talent of Sanya Institute of Deep-sea Science and Engineering, Chinese Academy of Sciences (SIDSSE-QN-201401), and the Sanya Key Laboratory of Marine Mammal and Marine Bioacoustics (L1402). P.Z and J.L. contributed equally to this paper.

Atkinson, S. (1997). "Reproductive biology of seals," Rev. Reprod. 2, 175-194.

Ballard, K. A., and Kovacs, K. M. (1995). "The acoustic repertoire of hooded seals (Cystophora-cristata)," Can. J. Zool. 73, 1362-1374.

Beier, J. C., and Wartzok, D. (1979). "Mating behaviour of captive spotted seals (Phoca largha)," Anim. Behav. 27, 772-781.

Bigg, M. (1981). "Harbour seal, Phoca vitulina and Phoca largha," in Handbook of Marine Mammals 2. Seals, edited by S. Ridgway and R. Harrison (Academic, New York), pp. 1-28.

Boness, D. J., Bowen, W. D., and Oftedal, O. T. L. (1994). "Evidence of a maternal foraging cycle resembling that of otariid seals in a small phocid, the harbor seal," Behav. Ecol. Sociobiol. 34, 95-104.

Boveng, P. L., Bengtson, J., Buckley, T., Cameron, M., Dahle, S., Kelly, B., Megrey, B., Overland, J., and Williamson, N. (2009). "Status review of the spotted seal (Phoca largha)" (U.S. Dept. Commer., NOAA Tech. Memo NMFS-AFSC-200).

Gailey-Phipps, J. (1984). "Acoustic communication and behavior of the spotted seal (Phoca largha)," Ph.D. dissertation, The Johns Hopkins University, Baltimore, MD. 
Insley, S. J. (1992). "Mother-offspring separation and acoustic stereotypy: A comparison of call morphology in two species of pinnipeds," Behaviour 120, $103-121$.

Insley, S., Phillips, A. V., and Charrier, I. (2003). "A review of social recognition in pinnipeds," Aquat. Mamm. 29, 181-201.

Jefferson, T. A., Webber, M. A., and Pitman, R. L. (2007). Marine Mammals of the World: A Comprehensive Guide to Their Identification (Academic, Pittsburgh, PA).

Kastelein, R. A., Gransier, R., and Hoek, L. (2013). "Comparative temporary threshold shifts in a harbor porpoise and harbor seal, and severe shift in a seal (L)," J. Acoust. Soc. Am. 134, 13-16.

Kastelein, R. A., Wensveen, P., Hoek, L., and Terhune, J. M. (2009). "Underwater hearing sensitivity of harbor seals (Phoca vitulina) for narrow noise bands between 0.2 and $80 \mathrm{kHz}$," J. Acoust. Soc. Am. 126, 476-483.

Khan, C. B., Markowitz, H., and McCowan, B. (2006). "Vocal development in captive harbor seal pups, Phoca vitulina richardii: Age, sex, and individual differences," J. Acoust. Soc. Am. 120, 1684-1694.

Muñoz, G., Karamanlidis, A. A., Dendrinos, P., and Thomas, J. A. (2011) "Aerial vocalizations by wild and rehabilitating Mediterranean monk seals (Monachus monachus) in Greece," Aquat. Mamm. 37, 262-279.

Phillips, A. V., and Stirling, I. (2001). "Vocal repertoire of South American fur seals, Arctocephalus australis: Structure, function, and context," Can. J. Zool. 79, 420-437.

Rautio, A., Niemi, M., Kunnasranta, M., Holopainen, I. J., and Hyvärinen, H. (2009). "Vocal repertoire of the Saimaa ringed seal (Phoca hispida saimensis) during the breeding season," Mar. Mammal Sci. 25 , 920-930.
Richardson, W. J., Greene, C. R., Jr., Malme, C. I., and Thomson, D. H. (2013). Marine Mammals and Noise (Academic, Pittsburgh, PA), pp. $1-576$.

Risch, D., Clark, C. W., Corkeron, P. J., Elepfandt, A., Kovacs, K. M., Lydersen, C., Stirling, I., and Van Parijs, S. M. (2007). "Vocalizations of male bearded seals, Erignathus barbatus: Classification and geographical variation," Anim. Behav. 73, 747-762.

Rogers, T. L. (2014). "Source levels of the underwater calls of a male leopard seal (L)," J. Acoust. Soc. Am. 136, 1495-1498.

Rugh, D. J., Shelden, K. E. W., and Withrow, D. E. (1997). "Spotted seals, Phoca largha, in Alaska," Mar. Fish. Rev. 59, 1-18.

Sauve, C. C., Beauplet, G., Hammill, M. O., and Charrier, I. (2015). "Acoustic analysis of airborne, underwater, and amphibious mother attraction calls by wild harbor seal pups (Phoca vitulina)," J. Mammal 96, 591-602.

Serrano, A. (2001). "New underwater and aerial vocalizations of captive harp seals (Pagophilus groenlandicus)," Can. J. Zool. 79, 75-81.

Tripovich, J. S., Canfield, R., Rogers, T. L., and Arnould, J. P. Y. (2008). "Characterization of Australian fur seal vocalizations during the breeding season," Mar. Mammal Sci. 24, 913-928.

Van Opzeeland, I., Kindermann, L., Boebel, O., and Van Parijs, S. M. (2008). "Insights into the acoustic behaviour of polar pinnnipeds current knowledge and emerging techniques of study," in Animal Behaviour: New Research, edited by E. A. Weber and L. H. Krause (Nova Science Publishers, Hauppauge, NY), pp. 133-161.

Van Parijs, S. M., and Kovacs, K. M. (2002). "In-air and underwater vocalizations of eastern Canadian harbour seals, Phoca vitulina," Can. J. Zool. 80, $1173-1179$. 